\section{Commentary: Robotic mitral valve surgery selection criteria: Screening algorithm or quantifying selection bias?}

\author{
J. Hunter Mehaffey, MD, MSc, and \\ Robert B. Hawkins, MD, MSc
}

Chemtob and colleagues ${ }^{1}$ assess the Cleveland Clinic screening algorithm for robotic surgery in patients with isolated degenerative mitral valve disease. They report that $60 \%$ of patients who were evaluated in the study met their criteria for a robotic approach. Furthermore, when they analyzed outcomes between patients undergoing conventional sternotomy compared with robotic approaches, they found no differences with outstanding outcomes in both groups. Based on these data, the authors suggest their screening algorithm is valid for selecting patients for a robotic approach.

Unfortunately, the article does not evaluate whether the screening algorithm that was applied is the optimal approach. That would require a comparison with other patient selection algorithms, not a comparison between those selected for robotic surgery or not. Consider the possibility that the screening algorithm selected those patients who would have achieved much better outcomes had they undergone sternotomy. Then, the observed equivalence in outcomes between robotic approach and sternotomy would have indicated a worse performance of robotic surgery. The scenario of the screening algorithm identifying patients who would have done better with sternotomy but rather had equivalent outcomes

From the Division of Thoracic and Cardiovascular Surgery, University of Virginia, Charlottesville, Va

Disclosures: The authors reported no conflicts of interest.

The Journal policy requires editors and reviewers to disclose conflicts of interest and to decline handling or reviewing manuscripts for which they may have a conflict of interest. The editors and reviewers of this article have no conflicts of interest.

Received for publication Dec 7, 2020; revisions received Dec 7, 2020; accepted for publication Dec 8, 2020; available ahead of print Jan 23, 2021.

Address for reprints: J. Hunter Mehaffey, MD, MSc, Department of Thoracic and Cardiovascular Surgery, University of Virginia, PO Box 800679, Charlottesville, VA 22908-0709 (E-mail: jhm9t@ virginia.edu).

J Thorac Cardiovasc Surg 2022;164:1088-9

$0022-5223 / \$ 36.00$

Copyright (c) 2020 by The American Association for Thoracic Surgery

https://doi.org/10.1016/j.jtcvs.2020.12.053

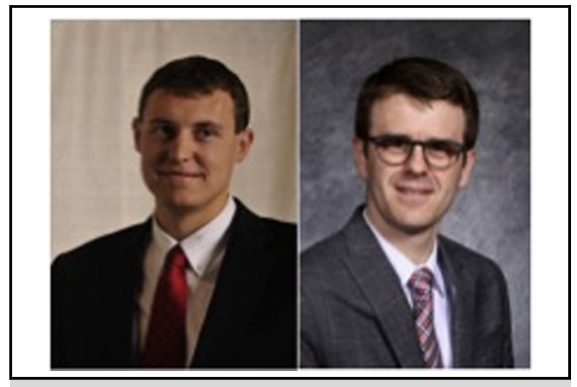

J. Hunter Mehaffey, MD, MSc, and Robert B. Hawkins, MD, MSc

\section{CENTRAL MESSAGE}

Excellent outcomes may be achieved with robotic mitral valve surgery in well-selected patients; however, an individualized approach should be based on center experience and surgeon comfort.

with the robotic approach refers to the counterfactual as described by Greenland and colleagues. ${ }^{2}$ The screening algorithm would then be nothing more than quantifying the selection bias. Furthermore, just because a patient does not meet criteria set forth by authors does not mean that he or she could not have an outstanding outcome if undergoing robotic mitral valve surgery by different surgeons at a different hospital.

Since the first report by Chitwood and colleagues ${ }^{3}$ of robotic mitral valve surgery, robotic heart surgery has continued to grow with a focus on optimizing approaches and identifying patient selection criteria. ${ }^{3}$ This study from the Cleveland Clinic, similar to the prior report by Gillinov on colleagues, ${ }^{4}$ on the first 1000 robotic mitral valve operations is another article leveraging their large clinical experience to help answer important clinical questions. The authors are to be commended on their robust experience and innovation as they push the field forward with outstanding outcomes. These data support the recent propensity-matched analysis by Hawkins and colleagues, showing robotic mitral valve surgery is safe with good outcomes in well-selected patients. ${ }^{5}$ More importantly, perhaps this study highlights that patient selection should be based on center experience and surgeon comfort with techniques because there is no one-size-fits-all criteria. 


\section{References}

1. Chemtob RA, Weirup P, Mick SL, Javorski MJ, Burns DJP, Blackstone EH, et al. A conservative screening algorithm to determine candidacy for robotic mitral valve surgery. J Thorac Cardiovasc Surg. 2022;164:1080-7.

2. Greenland S, Brumback B. An overview of relations among causal modelling methods. Int J Epidemiol. 2002;31:1030-7.

3. Chitwood WR Jr, Nifong LW, Elbeery JE, Chapman WH, Albrecht R, Kim V, et al. Robotic mitral valve repair: trapezoidal resection and prosthetic annulo- plasty with the Da Vinci surgical system. J Thorac Cardiovasc Surg. 2000; 120:1171-2.

4. Gillinov AM, Mihaljevic T, Javadikasgari H, Suri RM, Mick SL, Navia JL, et al Early results of robotically assisted mitral valve surgery: analysis of the first 1000 cases. J Thorac Cardiovasc Surg. 2018;155:82-91.e82.

5. Hawkins RB, Mehaffey JH, Mullen MG, Nifong WL, Chitwood WR, Katz MR et al. A propensity matched analysis of robotic, minimally invasive, and conventional mitral valve surgery. Heart. 2018;104:1970-5.
See Article page 1080.

\section{Commentary: Building a successful robotic mitral surgery program - one size does not fit all}

\author{
Irbaz Hameed, MD, and Arnar Geirsson, MD
}

In this issue of the Journal, Chemtob and colleagues ${ }^{1}$ report their conservative approach to determine candidacy for robotic mitral valve surgery at the Cleveland Clinic. Their study covers a large volume of patients spanning 5 years with excellent outcomes and deserves commendation. While a conservative screening strategy for robotic mitral surgery can confer good outcomes (particularly in emerging and less experienced robotic centers), such an approach may not be generalizable and should not curtail application of the technology or its innovation.

In their single-center observational study, the Cleveland group recommends echocardiographic and computed tomography imaging criteria for screening robotic mitral surgery patients that preclude patients with aortoiliac atherosclerosis, small femoral arteries, greater than mild aortic regurgitation, moderate or more mitral annular calcification, and left ventricular dysfunction. ${ }^{1}$ By applying this algorithm, outcomes comparable with a sternotomy-based approach were achieved, but $40 \%$ of the screened patients with

\footnotetext{
From the Division of Cardiac Surgery, Department of Surgery, Yale School of Medicine, New Haven, Conn.

Disclosures: Dr Geirsson is a member of Medtronic's Strategic Surgical Advisory Board. Dr Hameed reported no conflicts of interest.

The Journal policy requires editors and reviewers to disclose conflicts of interest and to decline handling or reviewing manuscripts for which they may have a conflict of interest. The editors and reviewers of this article have no conflicts of interest.

Received for publication Dec 12, 2020; revisions received Dec 12, 2020; accepted for publication Dec 14, 2020; available ahead of print Dec 25, 2020.

Address for reprints: Arnar Geirsson, MD, Division of Cardiac Surgery, Department of Surgery, Yale School of Medicine, PO Box 208039, New Haven, CT 06520 (E-mail: arnar.geirsson@yale.edu).

J Thorac Cardiovasc Surg 2022;164:1089-90 0022-5223/\$0.00

Published by Elsevier Inc. on behalf of The American Association for Thoracic Surgery

https://doi.org/10.1016/j.jtcvs.2020.12.065
}

Check for updates

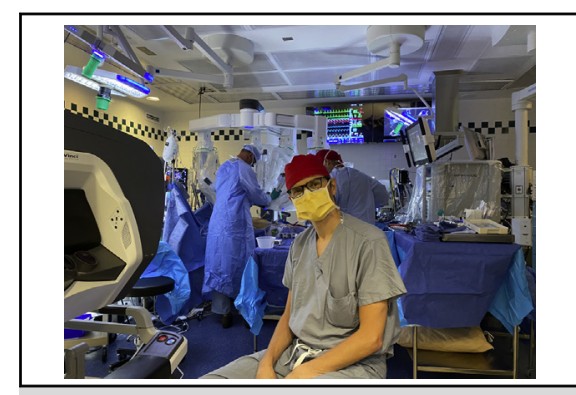

Dr Arnar Geirsson during a robotic mitral valve repair with the robotic team at Yale.

CENTRAL MESSAGE

The establishment of a success-

ful robotic mitral surgery pro-

gram is a complex, multitiered

process involving institutional,

surgeon-, and patient-related

variables.

isolated degenerative mitral valve disease were excluded. This strict approach may be feasible in extremely highvolume centers such as the Cleveland Clinic but not in an average high-volume cardiac surgery center in the United States with limited mitral surgery volume and modest robotic infrastructure. In such centers, excellent outcomes can in fact be achieved using more aggressive selection criteria as previously documented. ${ }^{2}$ It is further possible that due to nonrandomization of patients in the study by Chemtob and colleagues, ${ }^{1}$ confounders unrelated to the screening algorithm such as surgeon experience and treatment allocation bias were present, which further limit the generalizability of their proposed screening criteria to other centers.

Despite the impressive benefits of robotic mitral surgery, unfortunately only few centers worldwide have been able to establish successful and enduring robotic mitral surgery programs. The maintenance of a robust program requires 